\title{
Presentation Pattern of Lower Extremity Endovascular Intervention versus Percutaneous Coronary Intervention
}

\author{
Mitsuyoshi Takahara1, 2, 3, Osamu lida ${ }^{1,4}$, Shun Kohsaka1, 5, Yoshimitsu Soga ${ }^{1,6}$, Masahiko Fujihara ${ }^{1,7}$, \\ Toshiro Shinke ${ }^{1,8}$, Tetsuya Amano ${ }^{1,9}$, and Yuji Ikari ${ }^{1,10}$ on behalf of the J-EVT and J-PCI investigators
}

${ }^{1}$ The Japanese Association of Cardiovascular Intervention and Therapeutics, Tokyo, Japan

${ }^{2}$ Department of Diabetes Care Medicine, Osaka University Graduate School of Medicine, Osaka, Japan

${ }^{3}$ Department of Health Quality Assessment, The University of Tokyo, Tokyo, Japan

${ }^{4}$ Cardiovascular Center, Kansai Rosai Hospital, Hyogo, Japan

${ }^{5}$ Department of Cardiology, Keio University School of Medicine, Tokyo, Japan

${ }^{6}$ Department of Cardiology, Kokura Memorial Hospital, Fukuoka, Japan

${ }^{7}$ Department of Cardiology, Kishiwada Tokushukai Hospital, Osaka, Japan

${ }^{8}$ Division of Cardiovascular Medicine, Department of Internal Medicine, Showa University School of Medicine, Tokyo, Japan

${ }^{9}$ Department of Cardiology, Aichi Medical University, Aichi, Japan

${ }^{10}$ Department of Cardiology, Tokai University, Tokyo, Japan

Aim: The aim of the current study is to describe the presentation pattern of symptomatic peripheral artery disease undergoing endovascular therapy (EVT) in comparison to symptomatic coronary artery disease undergoing percutaneous coronary intervention (PCI) based on data from nationwide databases.

Methods: Data were extracted from the nationwide procedural databases of EVT and PCI in Japan (J-EVT and J-PCI) between 2012 and 2017. The presentation pattern was investigated using a Poisson regression model, including the month, seasonality, and weekend (versus weekday) as the explanatory variables. Seasonality was expressed as a cosine function of a 12-month period, and its significance was evaluated using the Fisher-Yates shuffle method.

Results: A total of 41,906 and 62,585 cases underwent EVT for critical limb ischemia (CLI) and intermittent claudication (IC), respectively, whereas 518,858 and 504,139 cases underwent PCI for acute coronary syndrome (ACS) and stable angina (SA). The procedural volume increased by $21.6 \%, 12.3 \%, 4.5 \%$, and $3.6 \%$ per year in CLI, IC, ACS, and SA. CLI and ACS, but not IC or SA, showed a significant volume seasonality. Compared with ACS, CLI demonstrated a larger peak-to-trough ratio of seasonality $(1.75$ versus $1.21 ; P<0.001)$, and a later peak appearance (February-March versus January-February by 1.37 months; $P<0.001$ ). The procedural volume on weekends relative to weekdays was smaller for SA, IC, and CLI than for ACS. These distinct features were observed in a diabetic population and a non-diabetic population.

Conclusions: The current study analyzed nationwide procedural databases and demonstrated the presentation pattern of symptomatic PAD and CAD warranting revascularization.

Key words: Presentation pattern, Seasonal variation, Weekend volume, Endovascular therapy, Percutaneous coronary intervention

\section{Introduction}

A number of previous studies have investigated the presentation pattern of clinically significant coronary artery disease $(\mathrm{CAD})^{1-3)}$. However, data were so far limited regarding lower extremity peripheral artery

Address for correspondence: Osamu lida, The Japanese Association of Cardiovascular Intervention and Therapeutics, 2-20-8, Shinkawa, Chuo-ku, Tokyo, 1040033, Japan. E-mail: iida.osa@gmail.com

Received: September 27, 2019 Accepted for publication: October 20, 2019 
disease (PAD), another cardiovascular disease that has now become a global health problem ${ }^{4)}$ and attracted increasing clinical attention ${ }^{5-8)}$. We previously reported the seasonal variation of critical limb ischemia (CLI) undergoing endovascular therapy $(\text { EVT })^{\text {9) }}$, but it remained to be validated by nationwide databases. Furthermore, whether another major symptomatic manifestation of PAD, namely, intermittent claudication (IC), will also have seasonal variation is still unrevealed.

Symptomatic PAD, especially that resistant to conservative treatments, requires timely revascularization $^{4,10,11)}$, as does symptomatic CAD ${ }^{12}$. Recently, percutaneous technique has become increasingly popular in clinical practice, and endovascular procedures have markedly increased in volume ${ }^{13)}$. The presentation pattern directly affects pressure on hospital beds and medical staffing. For cardiovascular centers to take proper measures for PAD patients, its understanding is essential.

Given that the major percutaneous intervention at cardiovascular centers is currently percutaneous coronary intervention (PCI) for CAD, a clearer understanding of the distinctive features of PAD will be promoted through a comparative analysis of PAD and CAD. The aim of the current study is to describe the presentation pattern of symptomatic PAD undergoing EVT in comparison to symptomatic CAD undergoing PCI based on data from nationwide databases obtained during the same time interval.

\section{Methods}

The current study analyzed the data obtained from the national registry databases in Japan (J-EVT and J-PCI) between January 2012 and December 2017. The J-EVT and J-PCI are the nationwide multicenter registries of EVT and PCI in Japan, respectively, organized by the Japanese Association of Cardiovascular Intervention and Therapeutics. The association obliges interventionalists and their cardiovascular centers to register all EVT and PCI cases in the J-EVT and J-PCI for application for board certification and renewal. The registered data include clinical diagnosis, date of revascularization, and treated vessel territories. The data analysis was performed in accordance with the Declaration of Helsinki and was approved by the ethics committee of the Clinical Research Promotion Network in Japan.

\section{Study Population}

Between 2012 and 2017, 1,450,813 cases $(117,697$ lower extremity EVT cases and 1,333,116 PCI cases) were registered in the J-EVT and J-PCI. Of these, 104,491 cases underwent aortoiliac, femoropopliteal, and/or below-the-knee EVT for CLI or aortoiliac and/or femoropopliteal EVT for IC, and $1,022,997$ cases underwent PCI for acute coronary syndrome (ACS) or stable angina (SA).

\section{Variable Definitions}

CLI was determined when patients presented lower extremity rest pain or unhealed ulcers/gangrenes due to chronic severe ischemia. For PCI patients, AMI and unstable angina (UA) were referred to as ACS. AMI was further subclassified into ST-elevation myocardial infarction (STEMI) and non-STEMI (NSTEMI). As $4.6 \%$ of the AMI cases had missing information regarding their subclassification, these cases were excluded in the analysis with ACS cases further classified into STEMI, NSTEMI, and UA, whereas otherwise they were included.

Regions where interventions were performed were classified based on the seven branches of the Japanese Association of Cardiovascular Intervention and Therapeutics as follows: (1) Hokkaido region, (2) Tohoku region, (3) Kanto-Koshinetsu region, (4) Tokai-Hokuriku region, (5) Kinki region, (6) Chugoku-Shikoku region, and (7) Kyushu-Okinawa region (http://www.cvit.jp/about/branch.html).

\section{Statistical Analyses}

A $P$ value $<0.05$ was considered statistically significant, and $95 \%$ confidence intervals (CIs) are reported where appropriate. The presentation pattern (i.e., procedural volume) was investigated using a Poisson regression model in which the month, seasonality (seasonal fluctuation), and weekend (versus weekday) were treated as the explanatory variables and the length (days) of time unit was treated as the offset. Saturdays, Sundays, and national holidays were referred to as weekends, whereas Mondays to Fridays were referred to as weekdays. The time unit was set as weekends and weekdays per month. The month variable was coded as 1 (= January 2012) to 72 (=December 2017). The seasonality variable was expressed as a cosine function of a 12-month period, in which 1 to 12 corresponded to January to December. When the seasonality was found to be significant, the peak-totrough ratio and peak month were calculated from the cosine function; otherwise, the regression model was redeveloped with the seasonality term deleted. In theory, the seasonality can be proven when the amplitude of the cosine function (i.e., the absolute value of its regression coefficient) is larger than zero. However, a cosine function with a prespecified period may falsely fit to a random error, yielding a non-zero regression coefficient, even if no seasonality exists. We therefore 
tested its statistical significance by generating a 2,000time Fisher-Yates shuffle of the monthly case number adjusted for annual linear increase. The 95\% CIs and $P$ values of the model-derived parameters and their inter-CVD differences were determined using 2,000time bootstrap resampling. To minimize the impact of repeated interventions, the seasonality was also assessed after second and subsequent interventions for one person were excluded from the study population. Whether interventions were performed in the same patient was judged by the patient identification number given by the institution where the interventions were performed.

The analyses were also performed after stratifying the study population with the presence of diabetes mellitus. The presentation patterns of CLI and ACS in respective regions were also examined.

All statistical analyses were performed using $\mathrm{R}$ version 3.6.0 ( $\mathrm{R}$ Development Core Team, Vienna, Austria).

\section{Results}

A total of 41,906 and 62,585 cases underwent EVT for CLI and IC, respectively, whereas 518,858 and 504,139 cases underwent PCI for ACS and SA, respectively. The presentation patterns are shown in Table 1 and Fig. 1. During the study period, the procedural volume increased by $21.6 \%$ and $12.3 \%$ per year in EVT for CLI and IC, respectively, and it increased by $4.5 \%$ and $3.6 \%$ per year in PCI for ACS and SA. ACS and CLI showed a significant volume seasonality (both $P<0.001$ ), but SA and IC did not $(P=0.13$ and 0.31 , respectively). Compared with ACS, CLI demonstrated a larger peak-to-trough ratio (1.75 versus $1.21, P<0.001)$. The peak came in January to February in ACS, whereas, in CLI, it came in February to March, 1.37 (95\% CI: 1.25-1.49) months later than in ACS $(P<0.001)$. Among the ACS cases, STEMI, NSTEMI, and UA had a similar peak month, but their peak-to-trough ratios were slightly but significantly different. The procedural volume on weekends relative to weekdays was much smaller for SA $(3.9 \%)$, IC (4.0\%), and CLI (2.6\%) than for ACS (43.7\%). Among the ACS cases, the weekend-to-weekday ratio was the largest in STEMI (72.3\%), followed by NSTEMI (47.5\%) and UA $(16.1 \%)$.

When second and subsequent interventions were excluded from the study population, CLI again had a larger peak-to-trough ratio and a later peak appearance than ACS (both $P<0.001)$. In this limited population, the peak-to-trough ratio was 1.91 (1.84 to 1.97 ) in CLI versus 1.23 (1.22 to 1.24 ) in ACS, and the peak came in February to March (at 2.75 [2.64 to 2.86] months) in CLI versus January to February (at 1.56 [1.48 to 1.64$]$ month) in ACS.

A larger peak-to-trough ratio and a later peak appearance of CLI versus ACS, as well as the lack of significant seasonality in SA and IC, were observed in a diabetic population and a non-diabetic population (Table 2 and Fig. 2). We finally compared the seasonality between CLI and ACS in each region. During the study period, $5.7 \%$ of PCIs for ACS were registered in Hokkaido region, $6.1 \%$ in Tohoku region, $36.2 \%$ in Kanto-Koshinetsu region, $13.5 \%$ in TokaiHokuriku region, $17.3 \%$ in Kinki region, $9.1 \%$ in Chugoku-Shikoku region, and $12.1 \%$ in KyushuOkinawa region, whereas $7.9 \%$ of EVTs for CLI were in Hokkaido region, 3.9\% in Tohoku region, 35.5\% in Kanto-Koshinetsu region, 9.1\% in TokaiHokuriku region, $27.2 \%$ in Kinki region, $5.7 \%$ in Chugoku-Shikoku region, and $10.7 \%$ in KyushuOkinawa region. Statistical significance in a larger peak-to-trough ratio and a later peak appearance of CLI versus ACS was confirmed in all the regions, except for the peak appearance in Hokkaido and Chugoku-Shikoku regions (Table 3).

\section{Discussion}

The current study, based on an analysis of data from nationwide procedural databases, demonstrated the presentation pattern of symptomatic PAD and $\mathrm{CAD}$ warranting revascularization.

The application of EVT for PAD increased more rapidly in volume than that of PCI for CAD, indicating that increasing medical resources have been devoted to EVT for PAD in recent years. IC, like SA, lacked seasonality; by contrast, CLI had a significant volume seasonality, as did ACS. The seasonality will be empirically intuited by many interventionalists: cardiovascular centers generally become busier when winter comes. However, the present study further clarified that the presentation patterns were not identical between CLI and ACS. As indicated by the peak-totrough ratio, the volume difference between busy and slow seasons is more evident in CLI than in ACS. Pressure on hospital beds and medical staffing will change more markedly with the seasons in CLI. Furthermore, the peak lagged more than one month behind ACS (February to March versus January to February). A larger peak-to-trough ratio and a later peak appearance were reconfirmed after excluding the second and subsequently registered interventions for one patient from the study population. However, our analysis could not completely exclude the influence of repeated interventions because patient identification 
Table 1. Comparison of presentation pattern

\begin{tabular}{|c|c|c|c|c|c|}
\hline & \multirow{2}{*}{ Annual fold increase } & \multicolumn{3}{|c|}{ Seasonality } & \multirow{2}{*}{$\begin{array}{c}\text { Volume in weekends } \\
\text { (fold difference } \\
\text { vs. weekdays) }\end{array}$} \\
\hline & & $P$ value for seasonality & Peak-to-trough ratio & Peak month & \\
\hline SA & $\begin{array}{c}3.6 \%[3.5 \text { to } 3.8 \%] \\
(P<0.001)\end{array}$ & 0.13 & --- & --- & $\begin{array}{c}3.9 \%[3.8 \text { to } 4.0 \%] \\
(P<0.001)\end{array}$ \\
\hline CLI & $\begin{array}{c}21.6 \% \text { [20.9 to } 22.3 \%] \\
(P<0.001)\end{array}$ & $<0.001$ & $\begin{array}{c}1.75[1.71 \text { to } 1.80] \\
(P<0.001)\end{array}$ & $\begin{array}{c}2.74[2.64 \text { to } 2.84] \\
(P<0.001)\end{array}$ & $\begin{array}{c}4.0 \%[3.7 \text { to } 4.2 \%] \\
(P<0.001)\end{array}$ \\
\hline IC & $\begin{array}{c}12.3 \%[11.8 \text { to } 12.8 \%] \\
(P<0.001)\end{array}$ & 0.31 & --- & --- & $\begin{array}{c}2.6 \%[2.4 \text { to } 2.8 \%] \\
(P<0.001)\end{array}$ \\
\hline UA & $\begin{array}{c}5.1 \%[4.8 \text { to } 5.3 \%] \\
(P<0.001)\end{array}$ & $<0.001$ & $\begin{array}{c}1.18[1.17 \text { to } 1.19] \\
(P<0.001)\end{array}$ & $\begin{array}{c}1.43[1.28 \text { to } 1.57] \\
(P=0.13)\end{array}$ & $\begin{array}{c}16.1 \%[15.9 \text { to } 16.4 \%] \\
(P<0.001)\end{array}$ \\
\hline
\end{tabular}

Data represent estimates and $95 \%$ CIs. $P$ values for annual fold increase, peak-to-trough ratio, peak month, and volume on weekends are versus ACS in SA, CLI, and IC, and versus STEMI in NSTEMI and UA. The month coded as 1 to 12 indicates January to December. ACS, acute coronary syndrome; SA, stable angina; CLI, critical limb ischemia; IC, intermittent claudication; STEMI, ST-elevation myocardial infarction; NSTEMI, non-STEMI; UA, unstable angina.
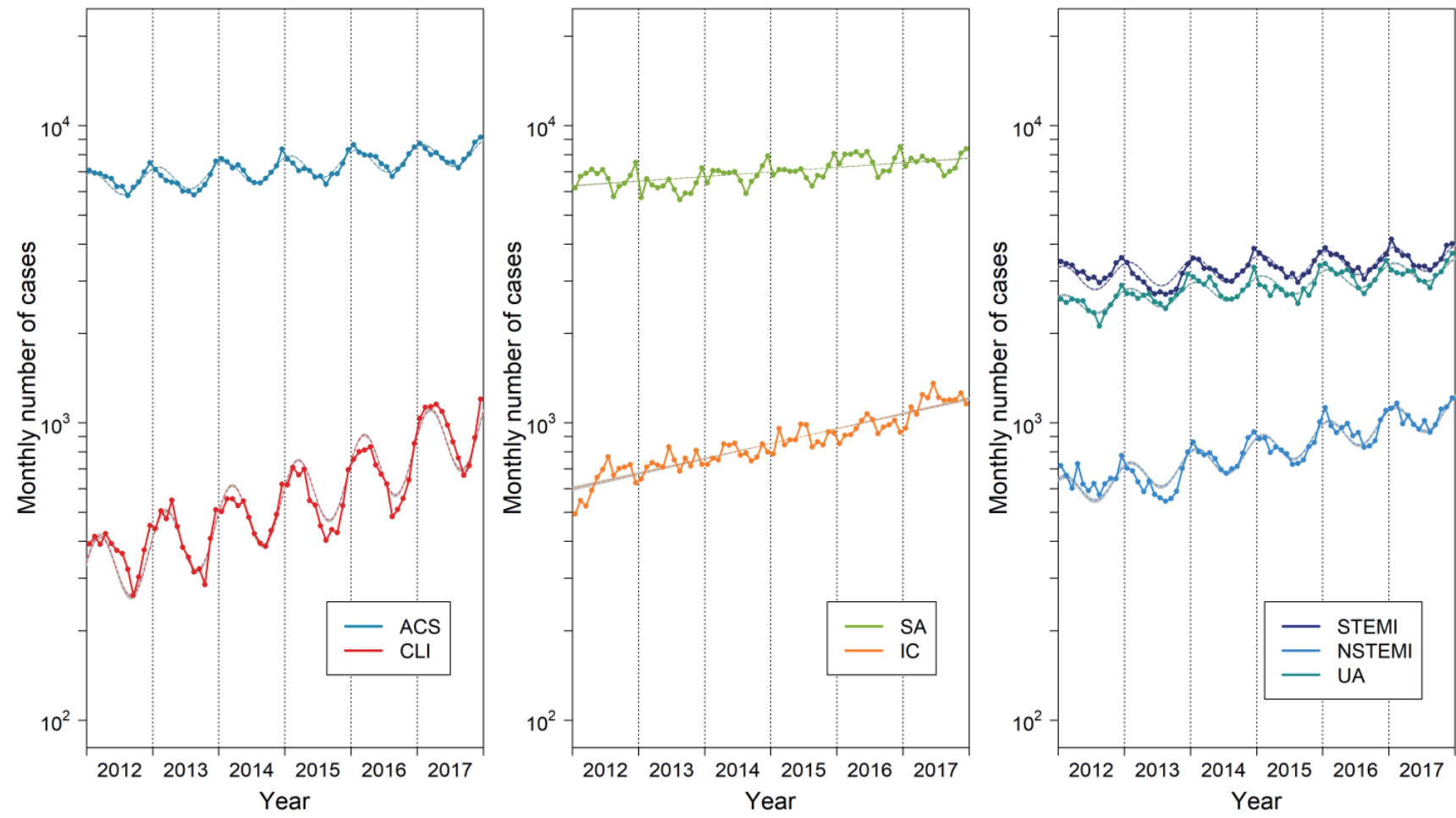

Fig. 1. Procedural volume between 2012 and 2017

Monthly volume was adjusted for the average length (days) of months during the study period, i.e., 30.4 days (10.1 weekends and 20.3 weekdays) per month. Dotted lines and shaded area represent estimates and 95\% CIs derived from Poisson regression models (see Table 1). ACS, acute coronary syndrome; CLI, critical limb ischemia; SA, stable angina; IC, intermittent claudication; STEMI, ST-elevation myocardial infarction; NSTEMI, non-STEMI; UA, unstable angina. 
Table 2. Comparison of presentation pattern in a diabetic and non-diabetic population

\begin{tabular}{|c|c|c|c|c|c|c|}
\hline & & \multirow{2}{*}{ Annual fold increase } & \multicolumn{3}{|c|}{ Seasonality } & \multirow{2}{*}{$\begin{array}{l}\text { Volume in weekends } \\
\text { (fold difference } \\
\text { vs. weekdays) }\end{array}$} \\
\hline & & & $P$ value for seasonality & Peak-to-trough ratio & Peak month & \\
\hline \multirow{3}{*}{ Diabetes } & SA & $\begin{array}{c}4.8 \%[4.6 \text { to } 5.1 \%] \\
(P<0.001)\end{array}$ & 0.056 & --- & --- & $\begin{array}{c}3.6 \%[3.5 \text { to } 3.7 \%] \\
(P<0.001)\end{array}$ \\
\hline & CLI & $\begin{array}{c}22.5 \%[21.5 \text { to } 23.4 \%] \\
(P<0.001)\end{array}$ & $<0.001$ & $\begin{array}{c}1.79[1.73 \text { to } 1.85] \\
(P<0.001)\end{array}$ & $\begin{array}{c}2.94[2.83 \text { to } 3.06] \\
(P<0.001)\end{array}$ & $\begin{array}{c}3.7 \%[3.3 \text { to } 4.0 \%] \\
(P<0.001)\end{array}$ \\
\hline & IC & $\begin{array}{c}14.6 \%[13.9 \text { to } 15.3 \%] \\
(P<0.001)\end{array}$ & 0.38 & -- & -- & $\begin{array}{c}2.4 \%[2.2 \text { to } 2.6 \%] \\
(P<0.001)\end{array}$ \\
\hline \multirow{2}{*}{ Non-diabetes } & CLI & $\begin{array}{c}22.4 \%[21.1 \text { to } 23.6 \%] \\
(P<0.001)\end{array}$ & $<0.001$ & $\begin{array}{c}1.73[1.65 \text { to } 1.81] \\
(P<0.001)\end{array}$ & $\begin{array}{c}2.33[2.16 \text { to } 2.49] \\
(P<0.001)\end{array}$ & $\begin{array}{c}4.4 \%[3.9 \text { to } 4.9 \%] \\
(P<0.001)\end{array}$ \\
\hline & IC & $\begin{array}{c}12.6 \%[11.8 \text { to } 13.4 \%] \\
(P<0.001)\end{array}$ & 0.26 & --- & --- & $\begin{array}{c}2.8 \%[2.6 \text { to } 3.1 \%] \\
(P<0.001)\end{array}$ \\
\hline
\end{tabular}

Data represent estimates and $95 \%$ CIs. $P$ values for annual fold increase, peak-to-trough ratio, peak month, and volume on weekends are versus ACS. The month coded as 1 to 12 indicates January to December. ACS, acute coronary syndrome; SA, stable angina; CLI, critical limb ischemia; IC, intermittent claudication.

in the current study was totally dependent on the patient identification number that was given by each institution. A patient who underwent the first intervention at a center and the second one at another was expected to be given different identification numbers. Therefore, the possibility that a different seasonality of CLI versus ACS can be amplified by more likeliness to repeat interventions for CLI still remains due to their lower patency rates compared with PCI. In addition, a later peak appearance of CLI may reflect the difference in the post-onset time course of CLI versus ACS rather than that in the time of onset. CLI is a chronic disease, whereas ACS is an acute one. Even if the two diseases had the same time of onset, the treatment time of CLI could lag behind that of ACS due to this etiological difference. Delayed referral of CLI to a cardiovascular specialist, possibly due to the unawareness of the disease ${ }^{14,15)}$, may be also involved in this time lag. Nonetheless, the current study confirmed that pressure on hospital beds and medical staffing had a different seasonality between ACS and CLI. The procedural volume on weekends relative to weekdays was smaller for SA, IC, and CLI than for ACS. The weekend volume would reflect the clinical emergency of respective diseases.

The mechanisms of the seasonal variation of CLI were unknown. The seasonality was observed in a diabetic population and a non-diabetic population, indicating that some common mechanisms to patients with and without diabetes might be involved. One possible explanation is that cold stimuli would cause vasoconstriction and impair peripheral microvascular blood flow ${ }^{16,17)}$. However, these speculations will not fully explain why the seasonal variation were not observed in IC. Although a significantly larger peakto-trough ratio of CLI versus ACS was observed in all regions, the peak-to-trough ratio of CLI appeared to be attenuated in northern regions. Some geographic or climatic features (e.g., cooler versus warmer) might modify the peak-to-trough ratio. A later peak appearance of CLI versus ACS was not statistically significant in Hokkaido or Chugoku-Shikoku region, but it was in the rest regions. Whether the non-significance in the two regions come from some region-specific factors or just from a relatively small sample size of these regions remained unknown. Future studies will be needed to reveal the underlying mechanisms.

The study has some limitations. First, the current study analyzed cases undergoing percutaneous intervention and did not target those undergoing open bypass surgery. Whether surgical revascularization would demonstrate similar presentation patterns 

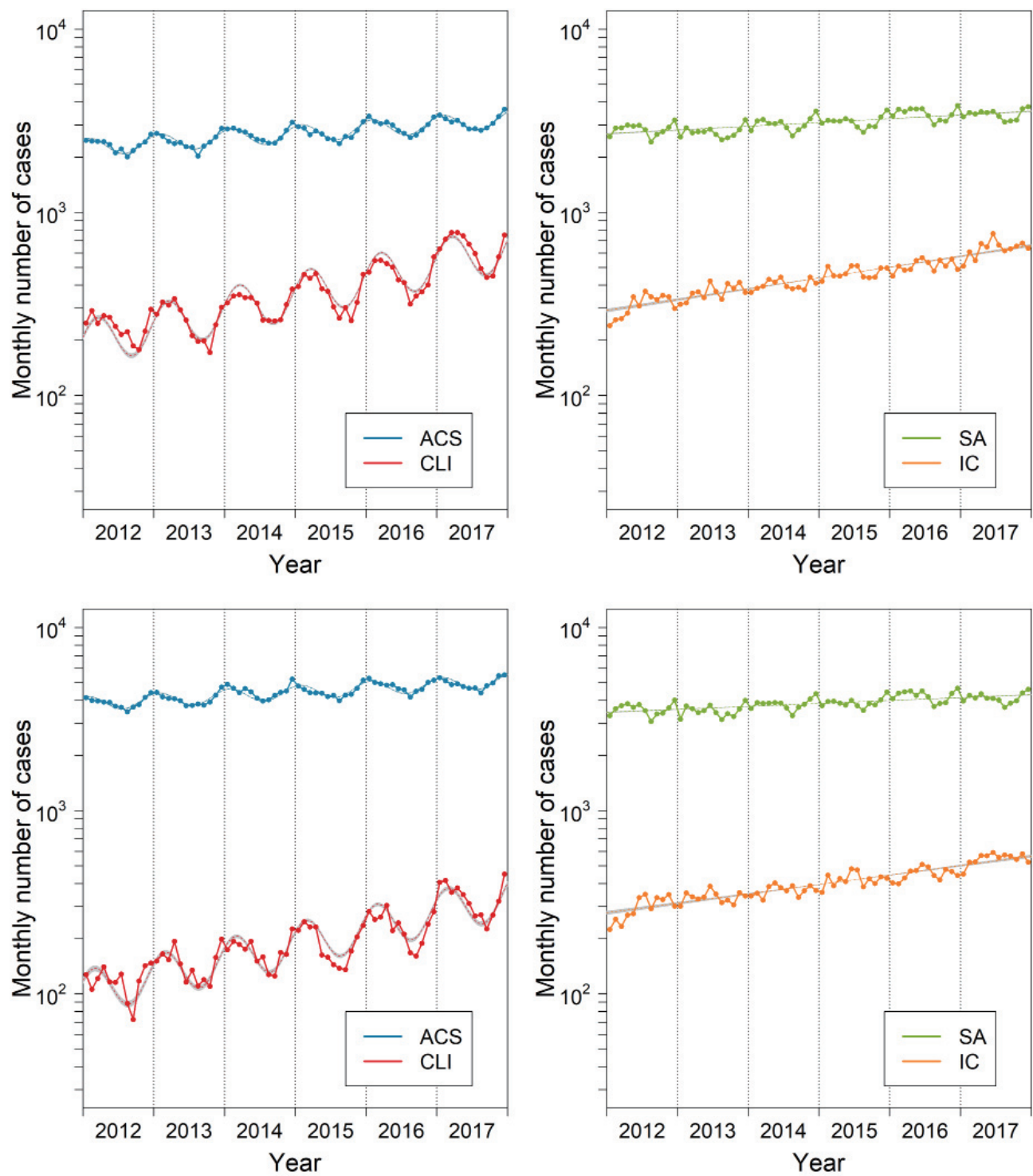

Fig. 2. Procedural volume between 2012 and 2017 in a diabetic (upper panels) and non-diabetic population (lower panels)

Monthly volume was adjusted for the average length (days) of months during the study period, i.e., 30.4 days (10.1 weekends and 20.3 weekdays) per month. Dotted lines and shaded area represent estimates and 95\% CIs derived from Poisson regression models (see Table 2). ACS, acute coronary syndrome; CLI, critical limb ischemia; SA, stable angina; IC, intermittent claudication.

remained unrevealed. Second, this study was based on a procedural database, and repeated interventions for a patient were judged only by the patient identification number that was given by each cardiovascular center. Third, the registry did not collect data on tissue loss (versus rest pain) or infection in CLI. These attributes are likely associated with the presence of diabetes mellitus ${ }^{18,}{ }^{19)}$, which is often accompanied by multiple comorbidities ${ }^{20,21)}$. This study confirmed a larger peak-to-trough ratio and a later peak appearance in CLI versus ACS, as well as the lack of season- ality in SA and IC, were observed in a diabetic population and a non-diabetic population. However, these data did not directly answer the question on the impact of tissue loss or infection status. Fourth, the current study analyzed PCI and EVT cases in Japan. Future studies in other countries will be needed to validate the current findings.

\section{Conclusion}

The current study analyzed nationwide databases 
Table 3. Seasonality of ACS versus CLI by region

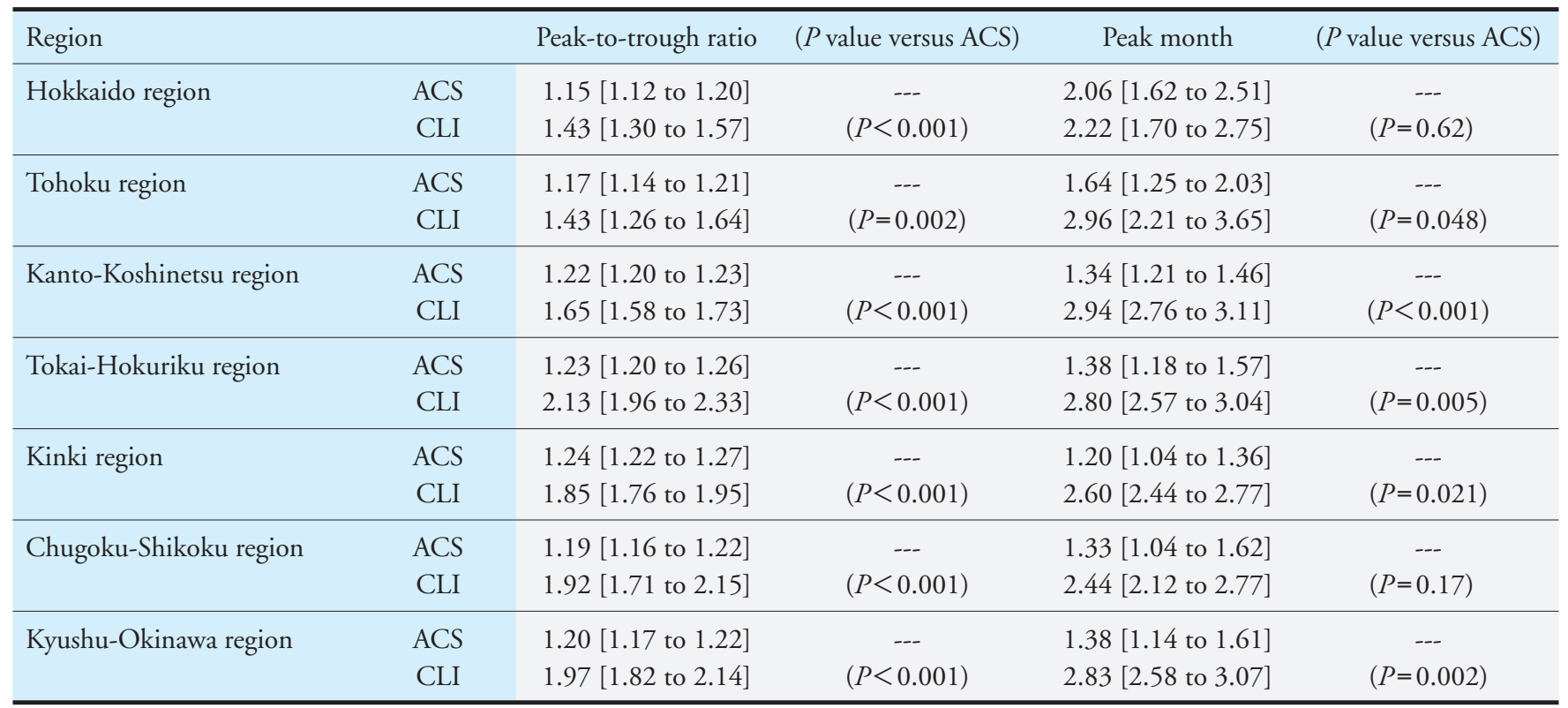

Data represent estimates and $95 \%$ CIs. $P$ values for peak-to-trough ratio and volume on weekends are versus ACS in the same region. The month coded as 1 to 12 indicates January to December. ACS, acute coronary syndrome; CLI, critical limb ischemia.

of percutaneous interventions and demonstrated the presentation patterns of EVT and PCI. EVT for PAD was more markedly increased in volume during the recent years. CLI and IC undergoing EVT and ACS and SA undergoing PCI had different seasonal presentation and weekend volume.

\section{Acknowledgments and Notice of Grand Support}

This study was supported by the Japan Society for the Promotion of Science (JSPS) KAKENHI Grant Number JP18K16199.

\section{Declaration of Conflicting Interests}

The authors declare that there is no conflict of interest.

\section{References}

1) Abramov A: Seasonal variations in myocardial infarction. Lancet, 1971; 1: 83

2) Rumana N, Kita Y, Turin TC, Murakami Y, Sugihara H, Morita Y, Tomioka N, Okayama A, Nakamura Y and Ueshima H: Seasonal pattern of incidence and case fatality of acute myocardial infarction in a Japanese population (from the Takashima AMI Registry, 1988 to 2003). The American journal of cardiology, 2008; 102: 13071311

3) Jia EZ, Xu ZX, Cai HZ, Guo CY, Li L, Zhu TB, Wang LS, Cao KJ, Ma WZ and Yang ZJ: Time distribution of the onset of chest pain in subjects with acute ST-elevation myocardial infarction: an eight-year, single-center study in China. PLoS One, 2012; 7: e32478. doi:32410.31371/ journal.pone.0032478 (accessed November 0032416, 0032012)

4) Aboyans V, Ricco JB, Bartelink MEL, Bjorck M, Brodmann M, Cohnert T, Collet JP, Czerny M, De Carlo M, Debus S, Espinola-Klein C, Kahan T, Kownator S, Mazzolai L, Naylor AR, Roffi M, Rother J, Sprynger M, Tendera M, Tepe G, Venermo M, Vlachopoulos C and Desormais I: 2017 ESC Guidelines on the Diagnosis and Treatment of Peripheral Arterial Diseases, in collaboration with the European Society for Vascular Surgery (ESVS): Document covering atherosclerotic disease of extracranial carotid and vertebral, mesenteric, renal, upper and lower extremity arteries Endorsed by: the European Stroke Organization (ESO) The Task Force for the Diagnosis and Treatment of Peripheral Arterial Diseases of the European Society of Cardiology (ESC) and of the European Society for Vascular Surgery (ESVS). Eur Heart J, 2018; 39: 763-816

5) Matsuo Y, Kumakura H, Kanai H, Iwasaki T and Ichikawa S: The Geriatric Nutritional Risk Index Predicts Long-Term Survival and Cardiovascular or Limb Events in Peripheral Arterial Disease. J Atheroscler Thromb, 2020; 27: 134-143

6) Ozkaramanli Gur D, Gur O, Guzel S, Akyuz A, Gurkan S, Alpsoy S, Gulec N and Koc F: Inflammatory Mediators Across the Spectrum of Ankle-Brachial Index. J Atheroscler Thromb, 2019; 26: 351-361

7) Fratta Pasini A, Stranieri C, Rigoni A, De Marchi S, Peserico D, Mozzini C, Cominacini L and Garbin U: Physical Exercise Reduces Cytotoxicity and Up-Regulates Nrf2 and UPR Expression in Circulating Cells of Peripheral Artery Disease Patients: An Hypoxic Adaptation? J 
Atheroscler Thromb, 2018; 25: 808-820

8) Fukunaga M, Kawasaki D, Nishimura M, Yamagami M, Fujiwara R and Nakata T: Clinical Effects of Planned Endovascular Therapy for Critical Limb Ischemia Patients with Tissue Loss. J Atheroscler Thromb, 2019; 26: 294301

9) Takahara M, Iida O, Soga Y, Hirano K, Yamaoka T, Kawasaki D, Suzuki K, Suematsu N, Shintani Y, Miyashita Y, Kaneto H and Shimomura I: Seasonal Variation in Critical Limb Ischemia Requiring Endovascular Therapy: An Analysis of a Multicenter Database of Japanese Patients with Critical Limb Ischemia Undergoing Endovascular Therapy. J Atheroscler Thromb, 2013; 20: 726732

10) Norgren L, Hiatt WR, Dormandy JA, Nehler MR, Harris KA, Fowkes FG, Bell K, Caporusso J, Durand-Zaleski I, Komori K, Lammer J, Liapis C, Novo S, Razavi M, Robbs J, Schaper N, Shigematsu H, Sapoval M, White C, White J, Clement D, Creager M, Jaff M, Mohler E, 3rd, Rutherford RB, Sheehan P, Sillesen H and Rosenfield K: Inter-Society Consensus for the Management of Peripheral Arterial Disease (TASC II). European journal of vascular and endovascular surgery: the official journal of the European Society for Vascular Surgery, 2007; 33 Suppl 1: S1-75

11) Gerhard-Herman MD, Gornik HL, Barrett C, Barshes NR, Corriere MA, Drachman DE, Fleisher LA, Fowkes FGR, Hamburg NM, Kinlay S, Lookstein R, Misra S, Mureebe L, Olin JW, Patel RAG, Regensteiner JG, Schanzer A, Shishehbor MH, Stewart KJ, Treat-Jacobson D and Walsh ME: 2016 AHA/ACC Guideline on the Management of Patients With Lower Extremity Peripheral Artery Disease: A Report of the American College of Cardiology/ American Heart Association Task Force on Clinical Practice Guidelines. J Am Coll Cardiol, 2017; 69: e71-e126

12) Ozaki Y, Katagiri Y, Onuma Y, Amano T, Muramatsu T, Kozuma K, Otsuji S, Ueno T, Shiode N, Kawai K, Tanaka N, Ueda K, Akasaka T, Hanaoka KI, Uemura S, Oda H, Katahira Y, Kadota K, Kyo E, Sato K, Sato T, Shite J, Nakao K, Nishino M, Hikichi Y, Honye J, Matsubara T, Mizuno S, Muramatsu T, Inohara T, Kohsaka S, Michishita I, Yokoi H, Serruys PW, Ikari Y, Nakamura M and Task Force on Primary Percutaneous Coronary Intervention of the Japanese Cardiovascular Interventional T: CVIT expert consensus document on primary percutaneous coronary intervention (PCI) for acute myocardial infarction (AMI) in 2018. Cardiovasc Interv Ther,
2018; 33: 178-203

13) Kawarada O, Zen K, Hozawa K, Ayabe S, Huang HL, Choi D, Kim SH, Kim J, Kato T, Tsubakimoto Y, Nakama T, Ichihashi S, Fujimura N, Higashimori A, Fujihara M, Sato T, Yan BP, Pang SY, Wongwanit C, Leong YP, Chua B, George RK, Yokoi Y, Motomura H and Obara H: Contemporary critical limb ischemia: Asian multidisciplinary consensus statement on the collaboration between endovascular therapy and wound care. Cardiovasc Interv Ther, 2018; 33: 297-312

14) Lovell M, Harris K, Forbes T, Twillman G, Abramson B, Criqui MH, Schroeder P, Mohler ER, 3rd, Hirsch AT and Peripheral Arterial Disease C: Peripheral arterial disease: lack of awareness in Canada. Can J Cardiol, 2009; 25: 39-45

15) Hirsch AT, Criqui MH, Treat-Jacobson D, Regensteiner JG, Creager MA, Olin JW, Krook SH, Hunninghake DB, Comerota AJ, Walsh ME, McDermott MM and Hiatt WR: Peripheral arterial disease detection, awareness, and treatment in primary care. JAMA, 2001; 286: 1317-1324

16) Watson HR, Robb R, Belcher G and Belch JJ: Seasonal variation of Raynaud's phenomenon secondary to systemic sclerosis. J Rheumatol, 1999; 26: 1734-1737

17) Gardner-Medwin JM, Macdonald IA, Taylor JY, Riley PH and Powell RJ: Seasonal differences in finger skin temperature and microvascular blood flow in healthy men and women are exaggerated in women with primary Raynaud's phenomenon. Br J Clin Pharmacol, 2001; 52: 17-23

18) Freisinger E, Malyar NM, Reinecke $H$ and Lawall $H$ : Impact of diabetes on outcome in critical limb ischemia with tissue loss: a large-scaled routine data analysis. Cardiovasc Diabetol, 2017; 16: 41

19) Reinecke $H$, Unrath $M$, Freisinger $E$, Bunzemeier $H$, Meyborg M, Luders F, Gebauer K, Roeder N, Berger K and Malyar NM: Peripheral arterial disease and critical limb ischaemia: still poor outcomes and lack of guideline adherence. Eur Heart J, 2015; 36: 932-938

20) Takahara M, Iida O, Fujita $Y$ and Haneda M: Clinical characteristics of Japanese diabetic patients with critical limb ischemia presenting Fontaine stage IV. Diabetol Int, 2019; 10: 231-235

21) Takahara M, Okuno S, Nakamura I, Iida O, Tsujimura T, Hata Y, Fujita Y and Haneda M: Prospective study on clinical characteristics of Japanese diabetic patients with chronic limb-threatening ischemia presenting Fontaine stage IV. Diabetol Int, 2019. doi.org/10.1007/s13340019-00399-5; 